African Crop Science Journal by African Crop Science Society is licensed under a Creative Commons Attribution 3.0 Uganda License. Based on a work at www.ajol.info/ and www.bioline.org.br/cs DOI: http://dx.doi.org/10.4314/acsj.v25i1.7S

\title{
PARTNERSHIPS IN HIGHLANDS OF RWANDA UNDER INTEGRATED AGRICULTURAL RESEARCH FOR DEVELOPMENT (IAR4D) ARRANGEMENTS
}

\author{
C. NGABOYISONGA, J. ODUOL ${ }^{1}$, J. MUGABO, M. TENYWA ${ }^{2}$, S.NYAMWARO $^{3}$, R. BURUCHARA ${ }^{4}$, \\ A.O. FATUNBI ${ }^{5}$ and A.A. ADEKUNLE ${ }^{5}$ \\ Rwanda Agriculture Board, P. O. Box 5016, Kigali-Rwanda \\ ${ }^{1}$ ICRAF, P. O. Box 30677, Nairobi-Kenya \\ ${ }^{2}$ Makerere University, College of Agricultural and Environmental Sciences, P. O. Box 7062, Kampala, Uganda \\ ${ }^{3}$ CIAT Uganda, P. O. Box 6247, Kampala, Uganda \\ ${ }^{4}$ CIAT Kenya, P. O. Box 823-00621, Nairobi, Kenya \\ ${ }^{5}$ FARA, 12 Anmeda Street, Roman Ridge, Accra, Ghana \\ Corresponding author: c.ngaboyisonga@yahoo.com, c.ngaboyisonga@rab.gov.rw
}

\begin{abstract}
The Integrated Agricultural Research for Development (IAR4D) concept was proposed to respond to the failures of Agriculture Research and Development (ARD) systems in Sub-Saharan Africa. The key element of implementation and success of IAR4D was action sites called agricultural Innovation Platform (IPs) and their counterfactual sites. Social Network Analysis (SNA) is used to explain social relationships and partnerships. This study explored the patterns of agricultural partnerships among stakeholders in the highlands of Rwanda under IAR4D. Data were collected in action sites that included Mudende, Gataraga, Remera and Rwerere; and in their counterpart counterfactual sites that comprised of Bigogwe, Nyange and Gacaca. Results showed that in action sites, stakeholders were linked to different and diversified partners. Furthermore, many stakeholders were connected to several partners through agricultural partnerships, hence creating complex social networks with high density and degree of distribution. In the counterfactual sites, however, stakeholders were exclusively linked to the same kind of partners, and one stakeholder was connected to one partner through probably non-agricultural partnerships. These facts demonstrated that IAR4D created dense interfaces, significantly improved the networking system, and delivered technologies and innovations.
\end{abstract}

Key Words: Action sites, counterfactual sites, IAR4D, partners, stakeholders

\section{RÉSUMÉ}

Le concept de Recherche Agricole Intégrée pour le Développement (IAR4D) a été proposé comme solution aux échecs des systèmes Recherches Agricoles et Développement (ARD) en Afrique Sub-Saharienne. L'élément principal de la réussite et du succès d'IAR4D était l'établissement des sites d'action appelés Plateformes Agricoles d'innovation (IPs) ainsi que leurs sites témoins. L'analyse du Réseau Sociale (SNA) est utilisée pour expliquer les rapports et les relations sociaux des acteurs et des partenaires. La présente étude avait pour objectif d'explorer les structures des relations socio-agricoles parmi les acteurs et les partenaires dans les hautes altitudes du Rwanda soumises à l'IAR4D. Les données ont été récoltées dans les sites d'action comprenant : Mudende, Gataraga, Remera et Rwerere ainsi que dans leurs contreparties sites témoins incluant Bigogwe, Nyange et Gacaca. Les résultats ont montré que dans les sites d'action, les acteurs étaient associés aux partenaires de natures différentes et un acteur était lié à plusieurs partenaires a la fois. Dans les sites témoins par contre, les acteurs étaient liés aux partenaires de mêmes natures que ceux-ci et un acteur était rarement lié à plus de deux 
partenaires. Ces faits ont montré que l'IAR4D a crée un réseau socio-agricole très dense et sophistiqué et ainsi a considérablement amélioré le réseau socio-agricole. Par conséquent, l’IAR4D peut être recommandé pour le transfert the technologies and des innovations agricoles.

Mots Clés : Acteurs, IAR4D, partenaires, sites d'action, sites témoins

\section{INTRODUCTION}

Sub-Saharan African (SSA) agriculture largely remains traditional and concentrated in the hands of smallholders. The key constraints to agriculture and farmers' livelihood improvements in the region include the linear top-down delivery of agricultural research, the failure for Agricultural Research and Development (ARD) systems to go beyond production, to encompass a comprehensive model that include markets, policy and natural resources management; the poor communication and partnerships among the actors within a commodity value chain (Stroud, 2004).

The concept of Integrated Agricultural Research for Development (IAR4D) was proposed to bring solutions to the failures of ARD systems (Adewale et al., 2013). The concept proposed operating principles and guidelines for stakeholders with different background and diverse interests to come together and critically analyse agricultural challenges, develop solutions and translate them into achievable targets. This operation brings the concerned actors to work together towards the fulfilment of common goals (Buruchara et al., 2013a). Therefore, the Sub Saharan Africa Challenge Program (SSA-CP) initiated the proof of IAR4D principles in three pilot learning sites in SSA that included Kano-Katsina-Maradi Pilot Learning Site (KKMPLS) in West Africa, Zimbabwe-Malawi-Mozambique Pilot Learning Site (ZMMPLS) in Southern Africa; and Lake Kivu Pilot Learning Site (LKPLS) in Central and Eastern Africa (Adewale et al., 2013). The LKPLS was established in the region bordering D.R. Congo, Rwanda and Uganda (Farrow et al., 2013).
The key element of implementation and success of the proof of IAR4D concept in LKPLS, was the establishment of action sites called agricultural Innovation Platform (IPs) (Ngaboyisonga et al., 2014). An agricultural IP was defined as a forum where stakeholders establish relationships and partnerships for improving a situation or resolving a constraint, hence, establishing a well-structured social network (Tenywa et al., 2011; 2013). In Rwanda, four functioning action sites, namely, Gataraga, Remera, Mudende and Rwerere and their three counterpart counterfactual sites: Nyange, Gacaca and Bigogwe were established. Bigogwe was counterfactual of two action sites, that is, the North part of Bigogwe which was the counterfactual of Mudende; while the South part was the counterfactual of Rwerere. Action and counterfactual sites were chosen in a manner that they were as similar as possible in terms of marketing, productivity and natural resources management so that the major difference was the fact that action sites received IAR4D treatments and the counterfactual sites did not receive any treatment (Farrow et al., 2013).

The principles of IAR4D are built upon four pillars; the first one involving integration of perspectives, knowledge, and actions of different stakeholders around a common theme or goal; while the second pillar requires integration of the learning that stakeholders gain from working together. The third pillar is integration of analysis, action and change across the different dimensions of development. The fourth pillar is integration of analysis, action and change at different levels of spatial, economic and social organisation (Adewale et al., 2013; Buruchara et al., 
2013b). In other words, stakeholders under IAR4D principles establish amongst themselves, known socio-agro-economic interactions and; hence, create complex socioagro-economic networks that are structured.

A social network is, thus a social structure made by individuals or organisations called nodes, which are connected or tied by one or more types of interdependencies such as friendship, kinship and common interest (Breiger, 2004; Butts, 2008). Hence, a social network is a map of specified ties or interactions between the nodes (Hoppe and Reinelt, 2010; Wonodi et al., 2012). In socioagricultural network, nodes are individuals or organisations drawn along the value chain of a commodity whereas the ties are the interactions between them like supply of inputs, training, provision of credit and dissemination of a new innovation or technology (Fungo et al., 2011; Jana et al., 2013; Ramirez, 2013).

Social network analysis (SNA) is a research methodology concerned with the explanation of social phenomena, using the structural and relational features of the network of actors (Lienert et al., 2013). Social network analysis provides an understanding of the goals, characteristics and relative influence of relevant groups and individual actors (Butts, 2008). In addition, SNA characterises the linkages between those actors, particularly in terms of how information is exchanged; who is included or excluded from the process, with emphasis on interaction between stakeholder groups (Fischer, 2013; Huszti et al., 2013). Social network analysis has become a popular way of analysing interactions between stakeholders in social networks in several disciplines such as medicine, natural resources management (Prell, 2009), agriculture extension (Jana et al., 2013; Ramirez, 2013) and information technology (Martino and Spoto, 2006).

When applied in action sites, the IAR4D system engages stakeholders to interact very actively and to establish interdependencies or partnerships among themselves depending on mutual benefits, interests and foreseen impacts to achieve a common goal. Therefore, this study was undertaken to analyse the patterns of partnerships between stakeholders and their partners in action sites under the IAR4D concept for technologies and innovation delivery.

\section{MATERIALS AND METHODS}

The study was conducted in seven sites established at sector administrative entity level in highlands of Rwanda. These sites were identified, characterised and used to prove the concept of IAR4D in LKPLS, as described by Tenywa et al. (2011) and Tenywa et al. (2013). The seven locations included four action sites or Innovation Platforms (IPs): Gataraga, Remera, Mudende and Rwerere; and three counterfactual sites: Nyange, Gacaca and Bigogwe. The northern part of Bigogwe was counterfactual for Mudende, whereas the southern part was the counterfactual for Rwerere (Table 1). All these sites were situated between latitudes: $1^{\circ} 25^{\prime} 07.91^{\prime \prime} S$ and $1^{\circ} 41^{\prime} 46.23^{\prime \prime} \mathrm{S}$, longitudes $29^{\circ} 19^{\prime} 04.55^{\prime \prime} \mathrm{E}$ and $29^{\circ} 56^{\prime} 32.25^{\prime \prime} \mathrm{E}$, and altitudes between 1850 masl and 2477, masl. The sites had complex cropping systems, characterised by the predominance of smallholder farmers, as described by Farrow et al. (2013).

Stakeholder analysis was conducted in the seven sites of the highlands of Rwanda in May 2010, two years after the implementation of IAR4D, following the procedures of Bryson (2004). In action sites, the list of organisation stakeholders and their individual representatives, were already established during several meetings with IP members. In counterfactual sites, the list of relevant organisation stakeholders and their representatives was established during meetings held with local authorities, opinion leaders and farmers representatives prior to stakeholder analysis.

The identified individual representatives of stakeholder organisations in each site (Table 
2) were invited to stakeholder meetings that were held at the sector headquarters of action and counterfactual sites. These meetings had the objective of identifying the types of agricultural partnerships and the links between stakeholders and their partners. During the meetings, the respondents were exposed to assessment questionnaire that was developed to map the stakeholders, their activities and the partner organisations. The assessment questionnaire was developed and pre-tested in other sites that were very far from both action and counterfactual sites.

In a plenary session, participants were then guided on how to complete the questionnaire. In situations where a participant was unable to read or write, facilitators interviewed the respondents and completed the questionnaire on their behalf. Also, in the questionnaire, emphasis was put on the partnerships where it was required to indicate the partner organisation with the stakeholder or the activities of individual partner, the type of organisation, if the partnership was formalised and the strength of the partnership. The strength of the partnerships had five levels: very weak, weak, medium, strong and very strong. The "very weak" partnerships between the stakeholders and the partners were established through electronic interactions such as phone calls, Short Message Systems (SMSs) and electronic mails while the "weak" partnerships were created by interactions faceto-face. The "medium partnerships" were

TABLE 1 . Market accessibility of the sites of the study in the highlands of Rwanda

\begin{tabular}{lll}
\hline Market access & Action sites & Counterfactual sites \\
\hline Excellent market access & $\begin{array}{l}\text { Gataraga } \\
\text { Remera }\end{array}$ & $\begin{array}{l}\text { Nyange } \\
\text { Gacaca }\end{array}$ \\
Poor market access & $\begin{array}{l}\text { Mudende } \\
\text { Rwerere }\end{array}$ & $\begin{array}{l}\text { Bigogwe North } \\
\text { Bigogwe South }\end{array}$ \\
\hline
\end{tabular}

TABLE 2. Stakeholders per category in a study on agricultural partnerships in highlands of Rwanda

\begin{tabular}{|c|c|c|c|c|c|c|}
\hline \multirow[t]{2}{*}{ Stakeholders per category } & \multicolumn{2}{|c|}{ Action sites } & \multicolumn{2}{|c|}{ Counterfactual sites } & \multicolumn{2}{|c|}{ Total } \\
\hline & Number & $\%$ & Number & $\%$ & Number & $\%$ \\
\hline Research & 1 & 0.9 & 1 & 0.8 & 2 & 0.9 \\
\hline Extension & 6 & 5.4 & 18 & 15.3 & 24 & 10.4 \\
\hline Marketing & 1 & 0.9 & 4 & 3.4 & 5 & 2.2 \\
\hline NGOs & 5 & 4.5 & 1 & 0.8 & 6 & 2.6 \\
\hline Input Supplier & 7 & 6.3 & 2 & 1.7 & 9 & 3.9 \\
\hline LADF & 62 & 55.4 & 83 & 70.3 & 145 & 63.0 \\
\hline COAS & 25 & 22.3 & 8 & 6.8 & 33 & 14.3 \\
\hline Faith based organization & 3 & 2.7 & 1 & 0.8 & 4 & 1.7 \\
\hline Others & 2 & 1.8 & 0 & 0.0 & 2 & 0.9 \\
\hline Total & 112 & 100.0 & 118 & 100.0 & 230 & 100.0 \\
\hline
\end{tabular}

NGOs $=$ Non-Government Organizations, LADF $=$ Local government, Administration and Farmers representatives, and COAS $=$ Cooperatives and Farmers Associations 
formed through exchange of written information whereas "strong partnerships" were established through exchange of physical materials and services. "Strong partnerships" were established by written documents endorsing them such as Memoranda of Understanding (MoU), Memoranda of Agreement (MoA) or a contracts.

Analysis of partnerships between the stakeholder organisations and their partner institutions was conducted using the SNA procedures as described by Ramez et al. (2013), Hoppe and Reinelt (2010) and Prell (2009), whereas the mapping was done using the net draw computer package as described by Clark (2006).

\section{RESULTS AND DISCUSSION}

Composition of stakeholder organisations. Two hundred and thirty respondents participated in the stakeholder analysis meetings, with $48.7 \%$ coming from action sites and $51.3 \%$ from counterfactual sites (Table 2). Local administration and farmers representatives (LADF) were the most predominant stakeholders $(62.6 \%)$, both in action sites $(54.5 \%)$ and counterfactual sites $(70.3 \%)$. However, they were slightly frequently higher in counterfactual sites than in action sites. Other stakeholders frequently present at significant extents in action sites were cooperatives and farmers associations (COAS) $(21.4 \%)$, extension agents $(8.0 \%)$, input suppliers (6.3\%) and NGOs (5.4\%); while in counterfactual sites they were extension agents (15.3\%) and Cooperatives and COAS $(6.8 \%)$.

The composition of respondents showed that they were more diverse types in action sites than in counterfactual sites. Furthermore, new stakeholders such as NGOs and input suppliers emerged in action sites (Table 2). The presence of such new stakeholders in the actions sites can be attributed to IAR4D approaches, which encompasses all aspects of the value chains and, hence increases, diversifies, and engages relevant stakeholders and partners in the network (Buruchara et al., 2013b). Overall, women represented $17 \%$ of all respondents: $20.5 \%$ of respondents in action sites and $13.6 \%$ in counterfactual sites (Fig. 1). The involvement of more women in action sites compared to counterfactual sites can be attributed to the incorporation of gender aspects in IAR4D (Adewale et al., 2013). Hence it can be used to reduce the gender gap in agricultural technological innovation transfer and adoption.

Partnerships analysis. In action sites, $31.1 \%$ of LADF stakeholders were linked to NGOs, $37.7 \%$ to other LADF partners, $14.8 \%$ to extension services, $24.6 \%$ to input suppliers and $8.2 \%$ to research partners. In COAS, $33.3 \%$ of them were connected to NGOs, $16.7 \%$ to LADF, $33.3 \%$ to input suppliers, $16.5 \%$ to extension and $12.5 \%$ to research. Furthermore, $8.3 \%$ of input supplier category of stakeholders was linked to extension, 8.3\% to research, $8.3 \%$ to $\mathrm{LADF}$ and $4.2 \%$ to NGOs; whereas $20.8 \%$ of extension category of stakeholders were linked to extension partners and $4.2 \%$ to research. NGO stakeholders were also present and $12.5 \%$ of them were connected to NGOs category of partners, $4.2 \%$ to LADF and $4.2 \%$ to research (Figs. 2 and 3).

The links of stakeholders to partners in action sites resulted in establishment of dense and dynamic agricultural relationships with partners, and an important flow of information under IAR4D scheme. Nyikahadzoi et al. (2013) found IPs under IAR4D provided access to information on markets, farming technologies and innovations. The establishment of dense and dynamic agricultural partnerships indicates that IAR4D could be an efficient mode of technological innovation transfer and adoption. Adekunle and Fatunbi (2012) found that with IAR4D, it was possible to conduct agricultural research 


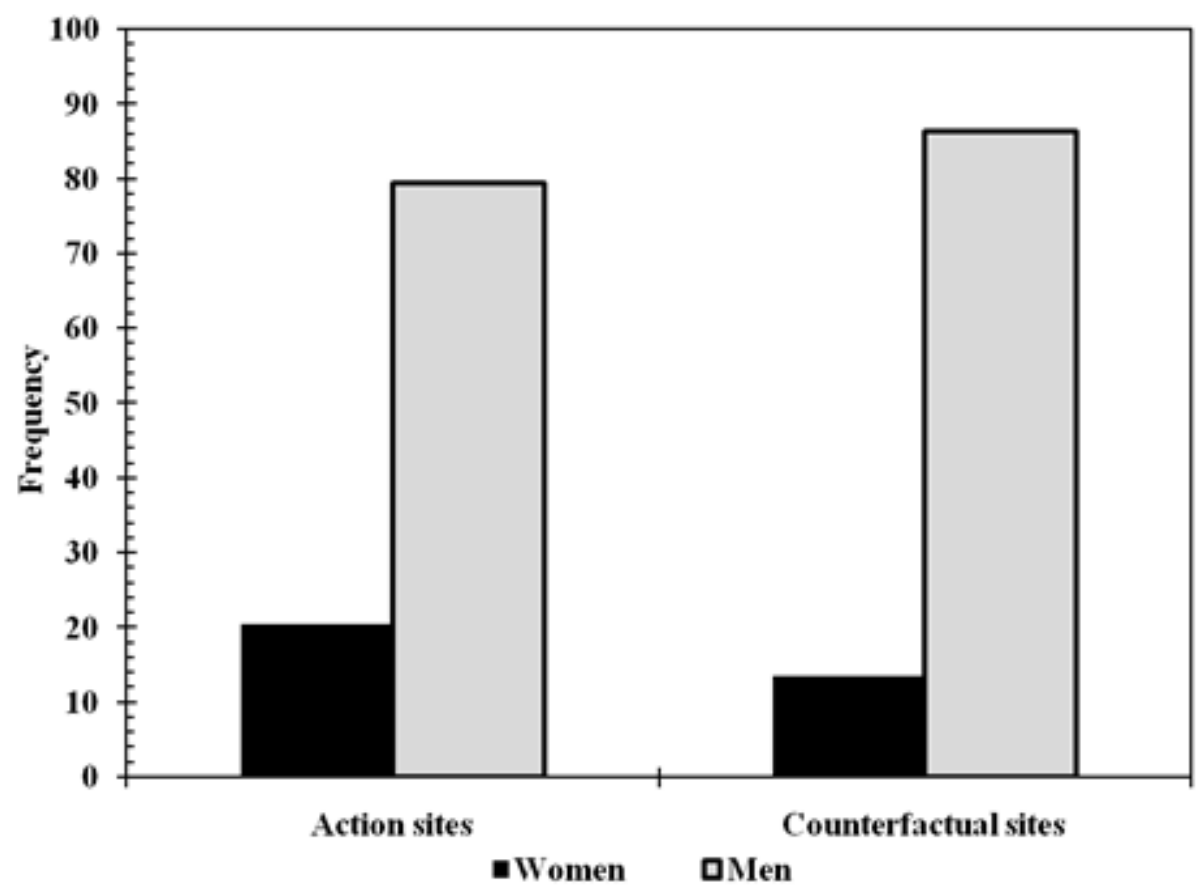

Figure 1. Distribution of respondents per gender among stakeholders in highlands of Rwanda.

and development activities in a mode that yield better returns to investment in terms of improved farm productivity, improved income, better livelihood and quality of life for the farmers.

It was clear that stakeholders established interactions with more partners of different types (Figs. 2 and 3). In several cases, a stakeholder was linked to more than two partners; and interfaces between stakeholders and partners were established in all directions i.e. horizontally and vertically, thus indicating complete departure from the linear system (Adewale et al., 2013; Buruchara et al., 2013b).

The agro-social networks of partnerships between and among stakeholders, and partner organisations in action sites under the IAR4D were quite complex, and were characterized by high density and degree of distribution; indicating very dynamic, active and interactive networks (Cohen and Havlin, 2007; Butts, 2008, Fungo et al., 2011; Hofstad, 2014).
Nkonya et al. (2013) and Ngaboyisonga et al. (2014) reported that stakeholders in IPs under IAR4D were connected to the partners because of mutual and potential benefits, interests, contributions and potential impact they could achieve in order to realise the common objectives.

The frequent partners linked to various stakeholders included NGOs (27.7\%), LADF (26.8\%), input suppliers $(20.5 \%)$, extension $(18 \%)$ and research (10.7\%). Moreover, $42.0 \%$ of stakeholders established partnerships with two or more partners; whereas $16.0 \%$ of them established partnerships with four or more partners (Figs. 2 and 3). Additionally, $54.8 \%$ of partnerships were formalised, meaning they were established through a memorandum of agreement or any other written document; while the rest were not formalised (Fig. 3). Most of the partnerships had medium strengths (32.4\%). However, very strong partnerships $(25.4 \%)$ were highly frequent as well. Together, strong and very 


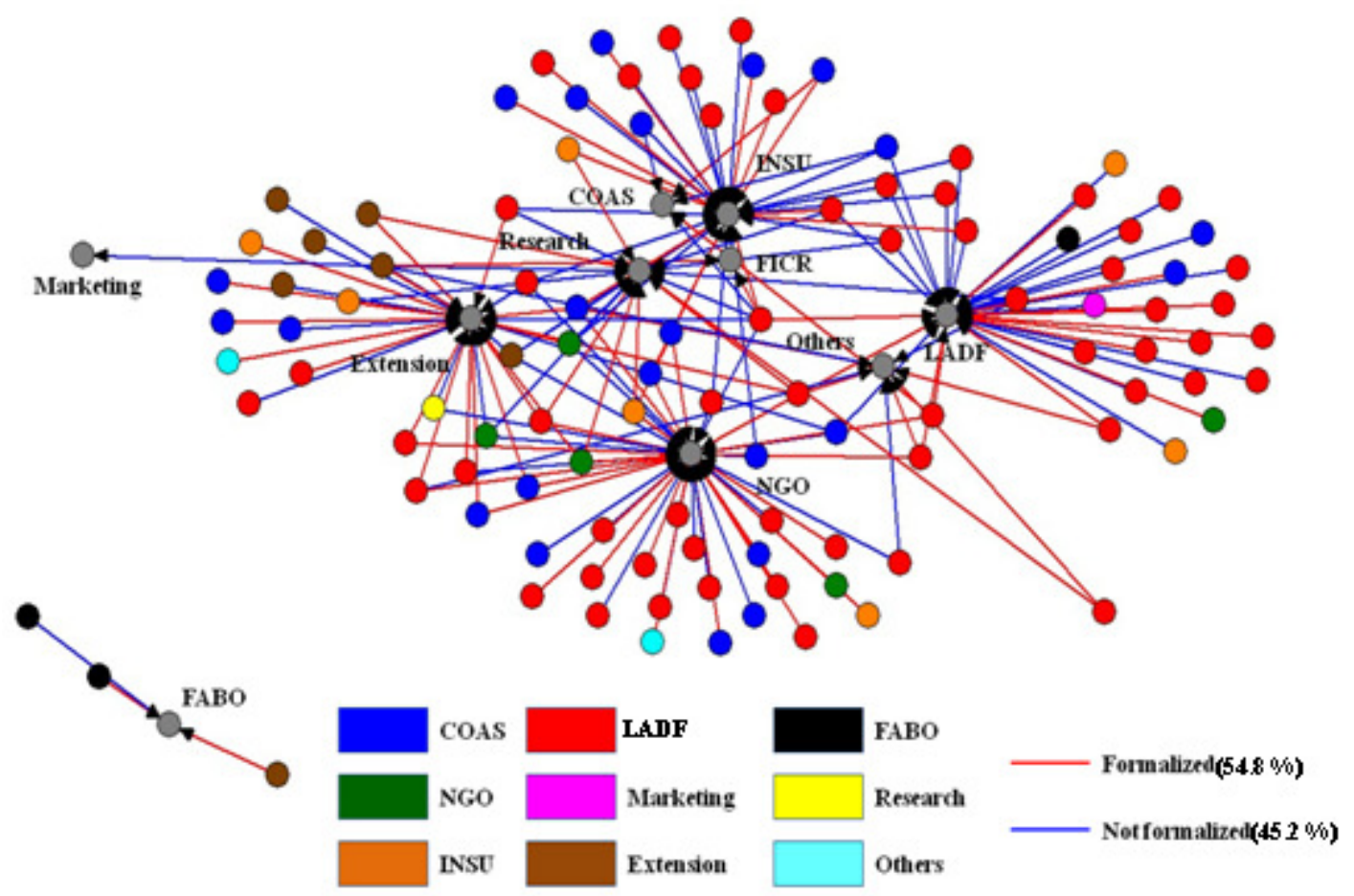

Frequent partners

NGOs: $27.7 \% \quad$ LGAF: $26.8 \%$

Extension: $18 \% \quad$ Research: $10.7 \%$
Input suppliers: $20.5 \%$

Figure 2. Formal partnership among agricultural stakeholders in action sites in highlands of Rwanda. The colour of the circle at arrow tail shows the organisation that the respondent represented while the circle at the arrow head shows the partner that the respondent mentioned to be linked with. NGO: Non-Government Organisations, INSU: Input Suppliers, LADF: Local Government, Administration and Farmers Representatives, COAS: Cooperatives and Farmers' Associations, FABO: Faith Based Organisation, FICR: Financial and Credit Organisations.

strong partnerships were frequent at $37.1 \%$ (Fig. 3).

In action sites under IAR4D, the most popular partners were those that provided agricultural inputs such as NGOs and input suppliers (Figs. 2 and 3). Furthermore, most of the partnerships were formalised and had medium to very strong linkages and, hence, were durable and sustainable (Adewale et al., 2013; Buruchara et al., 2013b). This was an important evidence that IAR4D increased and directed the relationships towards relevant partners capable of responding efficiently to the needs of the stakeholders; and hence accelerated the achievements of goals. Mango et al. (2015) pointed out that IAR4D could be recommended over other ARD models as an approach that addresses household food security through increased agricultural production.

In the counterfactual sites, all LADF stakeholders established relationships with LADF partners; while all extension stakeholders were linked to extension partners, all COAS stakeholders connected to COAS partners and all marketing stakeholders 


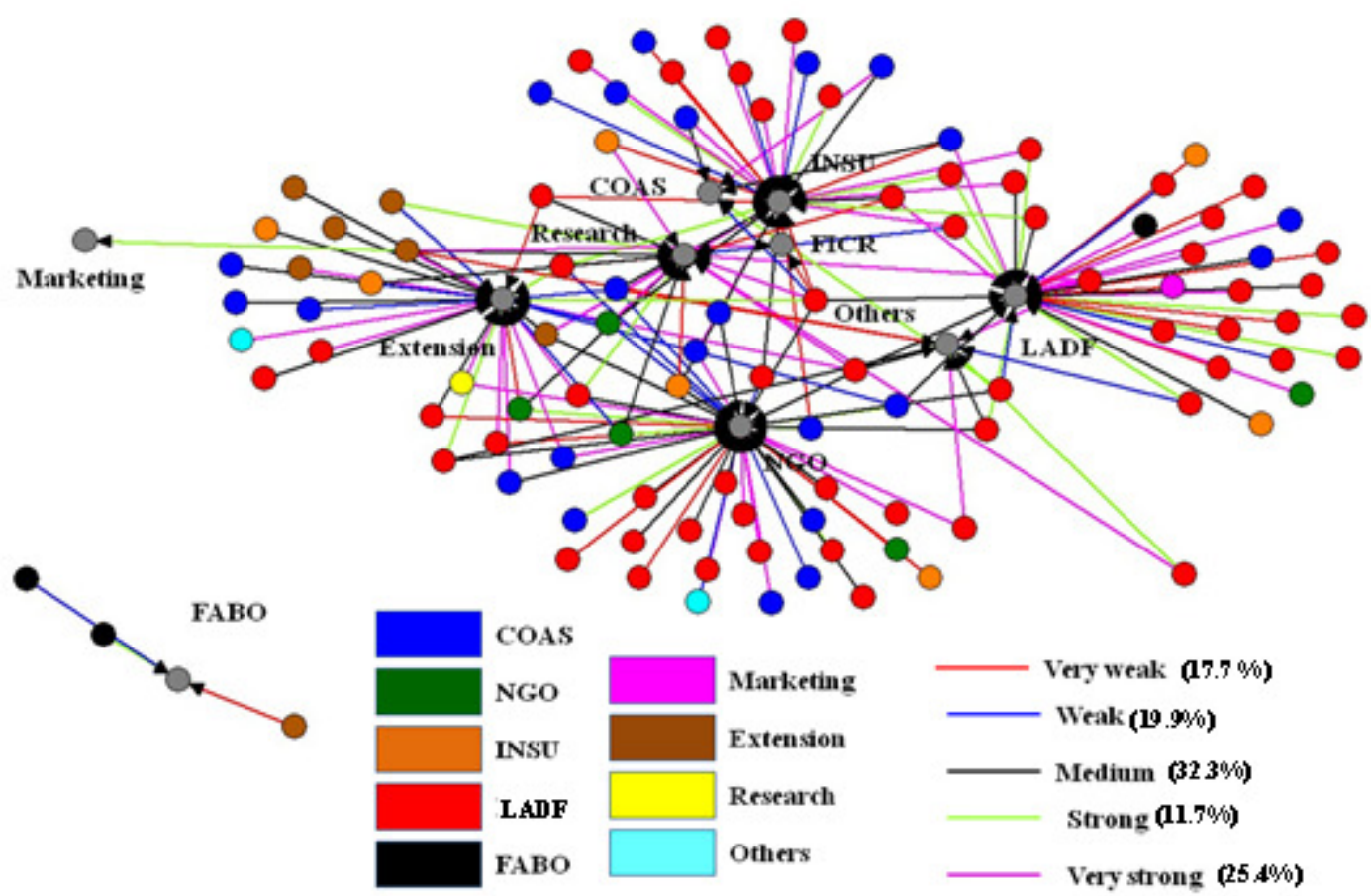

Frequent partners

NGOs: $27.7 \% \quad$ LGAF: $26.8 \%$

Extension: $18 \% \quad$ Research: $10.7 \%$
Input suppliers: $20.5 \%$

Figure 3. Strength of partnerships in action sites in highlands of Rwanda. The colour of the circle at arrow tail shows the organisation that the respondent represented while the circle at the arrow head shows the partner that the respondent mentioned to be linked with. NGO: Non-Government Organisations, INSU: Input Suppliers, LADF: Local Government, Administration and Farmers Representatives, COAS: Cooperatives and Farmers' Associations, FABO: Faith Based Organisation, FICR: Financial and Credit organisations.

also connected to marketing partners (Figs. 4 and 5). In fact, stakeholders were linked exclusively to partners of the same kind. Moreover, each stakeholder was linked to one partner (Figs. 4 and 5). Additionally, 59.5\% of partnerships were formalized (Fig. 4) whereas very weak and weak partnerships represented $49.4 \%$ (Fig. 5).

The agro-social networks of partnerships (ties) between and among stakeholders, and partners (nodes) in counterfactual sites under ARD systems, were very simple where nodes (stakeholders and their partners) were connected to others with only one link (one tie). Furthermore, they were characterised by absence of dynamism; they were inactive and passive. Stakeholders exclusively established relationships with partners of the same kind, probably because of lack of awareness of the benefits of networking with different partners, or lack of agricultural interactions between stakeholders and partners, such as provision of agricultural inputs. Further, the networks of partnerships were probably based on relationships other than agricultural partnerships, such as friendships, having a common marketing business and working in the same organisation (Hoppe and Reinelt, 2010; Lienert et al., 2013). Hence, the popular partners coincided with the dominant class of 

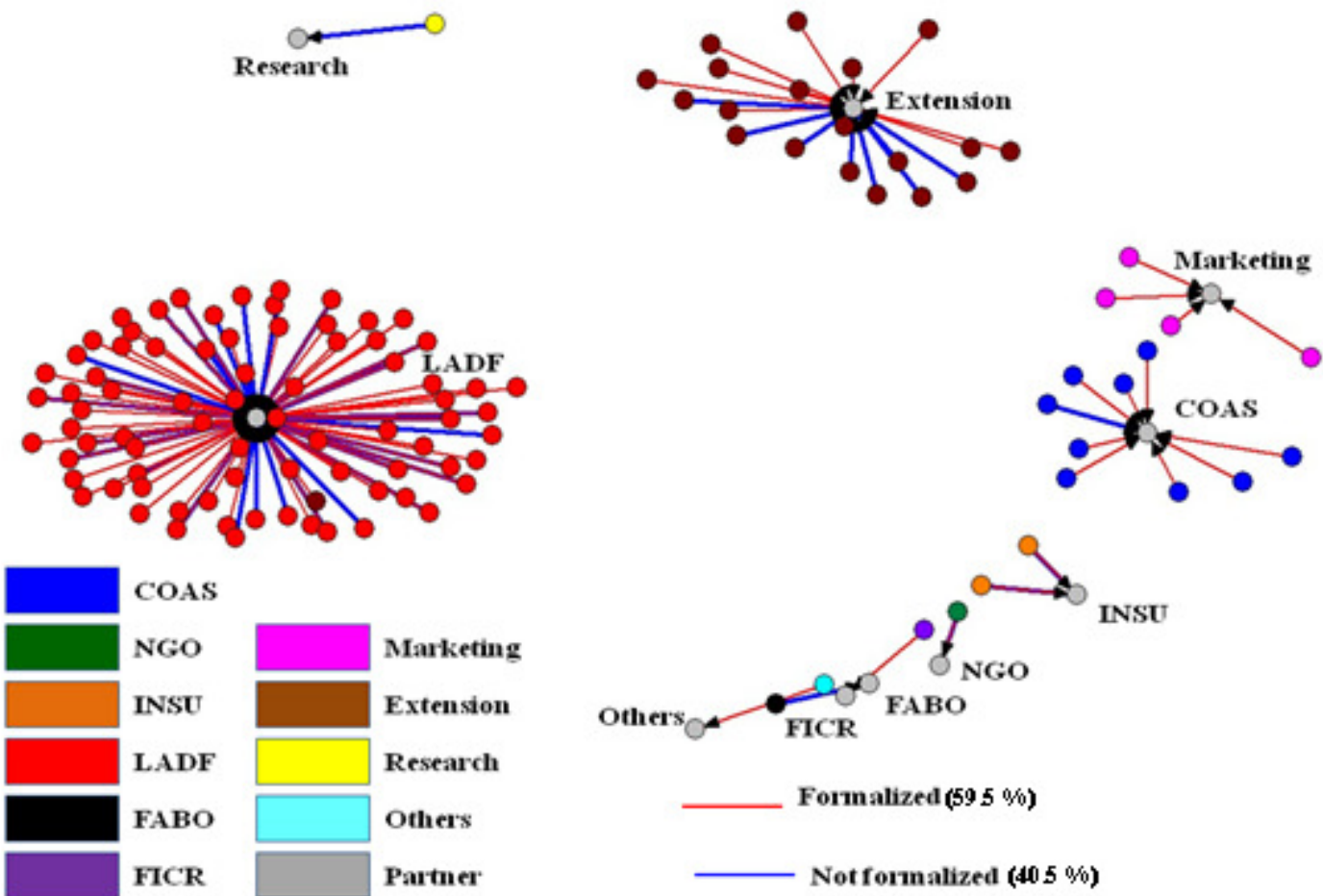

Figure 4. Formal partnership among agricultural stakeholders in counterfactual sites in highlands of Rwanda. The colour of the circle at arrow tail shows the organisation that the respondent represented while the circle at the arrow head shows the partner that the respondent mentioned to be linked with. NGO: Non-Government Organisations, INSU: Input Suppliers, LADF: Local Government, Administration and Farmers Representatives, COAS: Cooperatives and Farmers' Associations, FABO: Faith Based Organization, FICR: Financial and Credit Organisations.

stakeholders, implying that partnership was driven by service delivery but not agricultural input delivery.

\section{CONCLUSION}

The Integrated Agricultural Research for Development (IAR4D) concept was proposed as an innovative system that engages stakeholders to interact very actively and to establish interdependencies or partnerships among themselves depending on mutual benefits, interests and foreseen impacts to achieve a common goal, as such, IAR4D systems have several advantages over the traditional Agricultural Research and Development (ARD). Therefore, this study was undertaken to analyse the patterns of partnerships between stakeholders and their partners in action sites under the IAR4D concept for technologies and innovation delivery.

It has been found that IAR4D systems in action sites engages more women than ARD models in the counterfactual sites and, hence, may be one potential approach for reducing gender gaps in agricultural technological innovation transfer and adoption.

The IAR4D system in the action sites creates complex, dynamic, active and interactive agro-social networks of agricultural partnerships (ties) between stakeholders and partners (nodes). Furthermore, stakeholders are in different field of activities from the 

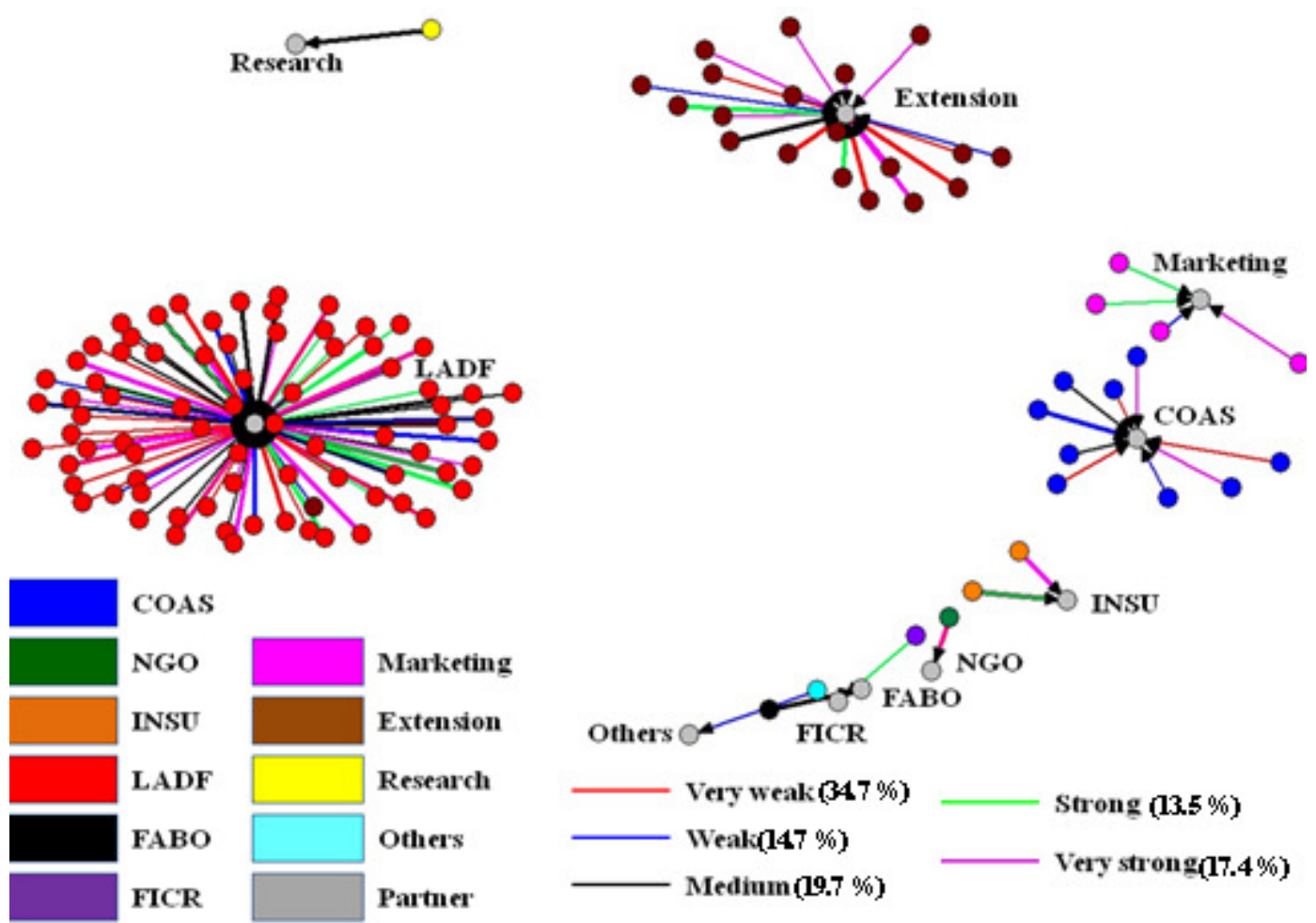

Figure 5. Strength of partnerships in counterfactual sites in highlands of Rwanda. The colour of the circle at arrow tail shows the organization that the respondent represented while the circle at the arrow head shows the partner that the respondent mentioned to be linked with. NGO: Non-Government Organizations, INSU: Input Suppliers, LADF: Local Government, Administration and Farmers Representatives, COAS: Cooperatives and Farmers' Associations, FABO: Faith Based Organization, FICR: Financial and Credit Organisations.

partners depending on the relevance of the service provided through establishment of partnerships. In the counterfactual sites under ARD system, however, the agro-social network is very simple and not active and each stakeholder is in relationship with one partner. Stakeholders and partners are in the same field of activities.

The presence of complex networking of agricultural partnerships among stakeholders and their partners in action sites implies that IAR4D is an efficient tool of agricultural technological innovation delivery and adoption than the top-down linear model of ARD. It creates more awareness through interfaces between stakeholders and brings more and tangible outputs.
It has been clearly shown that IAR4D system possesses several advantages over ARD model although the sample of stakeholders used in this study was probably not representative of all subsets of organisations and partners. It creates dense interfaces and enhances the networking system and hence delivers efficiently technologies and innovations. Therefore, it can be recommended as an efficient tool for agricultural research and innovation delivery as it addresses several gaps of ARD systems.

\section{ACKNOWLEDGEMENT}

We are indebted to the Forum for Agricultural Research in Africa (FARA) for supporting this 
work. Facilitation of CIAT as the lead institution as well as Rwanda Agricultural Board (RAB) for holding the task force leadership of the Rwanda IPs is acknowledged.

\section{REFERENCES}

Adekunle, A.A. and Fatunbi, A.O. 2012. Approaches for Setting-up MultiStakeholder Platforms for Agricultural Research and Development World Applied Sciences Journal 16 (7): 981-988.

Breiger, R.L. 2004. The analysis of social networks, pp 505-526. In: Hand book of data analysis; edited by Hardy, M. and A. Bryman, SAGE Publications, London, UK.

Bryson, J.M. 2004. What to do when stakeholders matter? Stakeholder identification and analysis. Public Management Review 6 (1): 21-53.

Buruchara, R., Adekunle, A.A., Fatunbi, A.O., Tenywa, M.M., Mugabo, J., Chiuri, W., Nyamwaro S.O., Majaliwa M., Tukahirwa J.M.B. and Kalibwani R. 2013a. Integrated Agricultural Research for Development: An Introduction. pp 5-20. In: Adekunle, A.A, Fatunbi, A.O., Buruchara, R. and Nyamwaro, S.O. (Eds). Integrated Agricultural Research for Development: from Concept to Practice. Forum for Agricultural Research in Africa (FARA), Accra, Ghana.

Buruchara, R., Tukahirwa, J., Kashaija, I., Farrow, A., Wanjiku, C., Rao, K.P.C., Adekunle, A.A., Kwesiga, F., Majaliwa, M.J.G., Nyamwaro, S.O., Kalibwani, R., Tenywa, M.M., Lunze, L., Mugabo J., Njeru R., Sanginga P., Mapatano S., Musana B., Ngabayisonga C., Murorunkwere, L. Bahiga, M. Ramazani, B. Wimba, P. Pali, J. Njuki, S. Mutabazi, R. Kamugisha, F., Fungo, B. and Kuule, M. 2013b. Principles, design and processes of integrated agricultural research for development: experiences and lessons from LKPLS under the SSACP. African Journal of Agricultural and Resource Economics 8 (3): 81-100.
Butts, C.T. 2008. Social network analysis: A methodological introduction. Asian Journal of Social Psychology 11: 13-41.

Clark, L. 2006. Network mapping as a diagnostic tool manual. Centro Internacional de Agricultura Tropical (CIAT). La Paz, Bolivia. p 31.

Cohen, R. and Havlin, S. 2007. Complex Networks: Structure, Stability and Function. Cambridge University Press. London, UK.

Farrow, A., Rao, K.P.C., Tenywa, M., Njeru, R., Kashaija, I., Kamugisha, R., Ramazani, M., Nkonya, E., Kayiranga, D., Lunze, L., Nabahungu, L., Kambale, K., Mugabo, J. and Mutabazi, S. 2013. Selecting sites to prove the concept of IAR4D in the Lake Kivu Pilot Learning Site. African Journal of Agricultural and Resource Economics 8 (3): 101-119.

Fischer, M. 2013. Applications of new techniques of data gathering and statistical analysis for Social Networks. ProcediaSocial and Behavioral Sciences 79: 1-3.

Hofstad, R. 2014. Random Graphs and Complex Networks. Vol. I. Department of Mathematics and Computer Science, Eindhoven University of Technology, Netherlands.

Fungo, B., Clark, L., Tenywa, M.M.,. Tukahirwa, J, Kamugisha, R., Birachi, E., Wanjiku, C., Bizoza, A.R., Wimba, B., Pali, P., Adewale, A. and Olowole, F. 2011. Networks among agricultural stakeholders in the Southwestern Highlands of Uganda. Journal of Agricultural Extension and Rural Development 3(7): 118-129.

Hoppe, B. and Reinelt, C. 2010. Social network analysis and the evaluation of leadership networks. The Leadership Quarterly 21: 600-619.

Huszti, E., Dávid, B. and Vajda, K. 2013. Strong tie, weak tie and in-betweens: A continuous measure of tie strength based on contact diary datasets. Procedia-Social and Behavioral Sciences 79: 38 - 61.

Jana, R., Bandyopadhyay, S. and Choudhuri, A.K. 2013. Reciprocity among farmers in 
farming system research: Application of Social Network Analysis. Journal of Human Ecology 41(1): 45-51 (2013).

Lienert, J., Schnetzer, F. and Ingold, K. 2013.

Stakeholder analysis combined with social network analysis provides fine-grained insights into water infrastructure planning processes. Journal of Environmental Management 125: 134-148.

Martino, F. and Spoto, A. 2006. Social Network Analysis: A brief theoretical review and further perspectives in the study of Information Technology. PsychNology Journal 4: 53 - 86.

Ngaboyisonga, C., Mugabo, J., Musana, B.S., Tenywa, M.M., Wanjiku, C., Mugabe, J. Murorunkwere, F., Ntizo S., Nyamulinda, B., Gafaranga, J., Tuyisenge, J., Nyamwaro, S.O. and Buruchara, R. 2014. Agricultural innovations that increase productivity and generate incomes: Lessons on identification and testing processes in Rwandan Agricultural Innovation Platforms. pp 371-384 In: Vanlauwe, B., van Asten, P., Blomme, G. (Eds.). Challenges and Opportunities for Agricultural Intensification of the Humid Highland Systems of Sub-Saharan Africa. Springer Cham Heidelberg, New York, USA.

Nkonya, E., Kato, E., Oduol, J., Pali, P. and Farrow, A. 2013. Initial impact of integrated agricultural research for development in East and Central Africa. African Journal of Agricultural and Resource Economics 8 (3):172-184.

Nyikahadzoi, K., Siziba, S., Mango, N., Zamasiya, B., and Adnkule, A.A. 2013. The Impact of Integrated Agricultural Research for Development on collective marketing among smallholder farmers of Southern Africa. Asian Journal of Agriculture and Rural Development (5): 321-336

Prell, C. 2009. Stakeholder analysis and social network analysis in natural resource management. Society and Natural Resources 22: 501-518.
Ramirez, A. 2013. The influence of social networks on agricultural technology adoption. Procedia-Social and Behavioral Sciences 79: 101 - 116.

Stroud, A. 2004. Understanding People, Their Livelihood Systems and the Demands and Impact of Innovations: A Synthesis. Uganda Journal of Agricultural Sciences 9: 797-818.

Tenywa, M.M., Farrow, A., Buruchara, R., Tukahirwa, J.M.B., Mugabe, J., Rao, K.P.C., Wanjiku, C., Nyamwaro, S.O., Kashaija, N.I., Majaliwa, M., Mapatano, S., Mugabo J., Ngaboyisonga, C., Ramazani, M.A., Mutabazi, S., Fungo, B., Pali, P., Njuki, J., Abenakyo, A., Opondo, C., Nkonya, E., Njeru, R., Lubanga, L., Wimba, B., Murorunkwere, F., Kuule, M., Mandefu, P., Kamugisha, R., Fatunbi, A.O. and Adekunle, A.A. 2013. Strategies for setting up innovation platforms in the Lake Kivu Pilot Learning Site. pp 20-40. In: Adekunle, A.A, A.O. Fatunbi, R. Buruchara and S.O. Nyamwaro (Eds). Integrated Agricultural Research for Development: from Concept to Practice. Forum for Agricultural Research in Africa (FARA), Accra, Ghana.

Tenywa, M.M., Rao, K.P.C., Tukahirwa, J.B., Buruchara, R., Adekunle, A.A., Mugabe, J., Wanjiku, C., Mutabazi, S., Fungo, B., Kashaija, I.N., Pali, P., Mapatano, S., Ngaboyisonga C., Farrow, A., Njuki, J. and Abenakyo, A. 2011. Agricultural Innovation Platform as a tool for development oriented research: Lessons and challenges in the formation and operationalization. Learning Publics Journal of Agriculture and Environmental Studies 2 (1): 117-146.

Wonodi, C.B., Privor-Dumm, L., Aina, M., Pate, A.M., Reis, R., Gadhoke, P. and Levine, O.S. 2012. Using social network analysis to examine the decision-making process on new vaccine introduction in Nigeria. Health Policy and Planning 27: 27-38. 